\title{
Research on Pathways of Non-Profit Organizations Involvement in Social Pension Service in China
}

\author{
Yuanting Wei \\ School of Public Affairs and Laws, Southwest Jiaotong University, Chengdu, China \\ Email:2068921002@qq.com
}

How to cite this paper: Wei, Y.T. (2018) Research on Pathways of Non-Profit Organizations Involvement in Social Pension Service in China. Open Access Library Journal, 5: e4558.

https://doi.org/10.4236/oalib.1104558

Received: March 31, 2018

Accepted: April 25, 2018

Published: April 28, 2018

Copyright $\odot 2018$ by author and Open Access Library Inc.

This work is licensed under the Creative Commons Attribution International License (CC BY 4.0).

http://creativecommons.org/licenses/by/4.0/

\begin{abstract}
As China's population aging advancement becomes more and more obvious, the social security system is insufficient to support the rapid huge aging society. The conditions of family-provide for the aged are weakened gradually while social pensions draw more and more attention. As a potential social capital, non-profit organization is an important force for assisting the work of care for the aged. This research focuses on the exploration of pathways by social survey. Through the analysis of existing literature and the data from questionnaire, the author focuses on the situations of non-profit organizations that participate in social pension service, including the current developmental situation, the internal and external predicament environments, etc. In conclusion, the results of the survey indicate that the majority of respondents are favor of their participation. However, faced with many predicaments, the non-profit organizations need to achieve a great-leap-forward development and improve the social credibility by strengthening the construction and management of themselves. In conclusion, combining with developed information technology, the networked cooperation and synergy of multiple principal resources may be the further development trend of social pension service model in the future.
\end{abstract}

\section{Subject Areas}

Sociology, Statistics

\section{Keywords}

Non-Profit Organizations, Social Pension Service, Pathways

\section{Introduction}

According to the United Nations Department of Economic and Social Affairs, 
the number of global population aged 60 years old or over is 962 million in 2017, which is expected to reach nearly 2.1 billion by 2050 [1]; In China, the number of population aged 60 years old or over is expected to reach 430 million by 2050 , which accounts for nearly $31.30 \%$ of their national total population [2]. Under the background of global aging, as a country with a so large population, China's elderly security systems have attracting plenty of attentions. Many scholars have been carrying on the research of China's supporting problem. Just as the China National Knowledge Infrastructure showed, there were 66,589 papers related to this research theme by 2017. From 2013 to 2017, more than 5000 papers were published each year. Moreover, the trend of research is still increasing.

With the development of modern social economy, the main body of the responsibility for the aged is gradually diversified and the social pension service appeared. Social pension service is a combination of multiple social subjects, including the government, family, communities, enterprises, nursing home and volunteers and so on. All of them participate in promoting the establishment of a social pension service system through social channels. As a beneficial supplement to family care, the emergence of social endowment is driven by a series of factors, such as the aging of society, the weakening of the family supporting and the imbalance between the supply and demand of the services. Just as discussed by Hongwei $\mathrm{Hu}$ et al., the social endowment has significant positive external effects, which can increase the resources supply for the elderly, alleviate the current contradiction of unbalanced social pension service, and promote the citizen's social responsibility [3]. Yaxian Qian thinks that the construction of social endowment service system in China mainly includes psychological care, spiritual comfort and social support for the elderly at present [4]. However, Yinghua Zhang and Yan Jiang insist that the construction of team is weak [5], and Wenbin Wei adds that the operation mechanism also needs to be perfected [6]. A total of 12,571 articles have been retrieved from the China National Knowledge Infrastructure by using the theme term "Social Pension Service" by 2017. At the same time, the visual analysis of these records showed that the key words in the top 20 of the usage included home-based care for the aged (1002), community endowment (448), endowment institution (337), family supporting (143) and so on. But there research related to non-profit organizations is very little at present. The existing researches usually analyze the social pension pattern by case or literature study. As we can see, historically studies lay emphasis on government, families, communities and nursing institution for the aged. Nevertheless, the research in this paper focuses on the participation of non-profit organizations in the social pension service.

There are two main purposes of this research, the first one is to understand the present situation of the non-profit organizations participating in social pension service through the questionnaire survey and field investigation, the second one is to explore the pathways for their better participation.

In the next section, Materials and methods will be introduced. In the Follow- 
ing, the research results will be presented. After analyzing and discussing the data, conclusions are drawn on providing appropriate recommendations on pathways of non-profit organizations involvement in social pension service.

\section{Analytical Method}

\subsection{Questionnaire Survey}

With a time span of 5 months, the questionnaire was designed and collected from the beginning of October 2017 to the end of January 2018. For the different age groups, a random sampling method was used to select the respondents. According to the current five-level administrative division in China, the final research sites were selected by drawing lots. Then we numbered the local residents according to their registration information. In the next, we adopt the method of random number table to select number. Finally, the corresponding list of people came into being. 1100 questionnaires were sent out and 1015 valid questionnaires were collected, which have an effective recovery rate of $92.27 \%$. The questionnaire is designed according to the principles of clarity of purpose, appropriateness of the topic and consistency of sentence understanding. In addition to the preface, the questionnaire consists of 8 questions: the first three is a basic information survey, mainly including the age, gender and occupation. The following five problems are carried out in five aspects: the perception of pension risk, the preference of the pension choice, the satisfaction of the social pension, the social approval degree of the organization and the assessment of the organizational current situation. The survey of the basic information of the investigators is mainly used to analyze the follow-up data.

\subsection{Data Analysis}

This data analysis uses SPSS statistical analysis software. There are two methods called the descriptive statistical analysis and cross-group frequency analysis. On the one hand, through the description of statistical analysis, the overall distribution and views on the social pension and non-profit organizations involvement in social pension service can be understood. Besides, the Chi-square test was used to analyze the different characteristics of respondents and the interaction relationship between different variables.

\section{Results}

\subsection{The Respondents' Composition}

Table 1 demonstrates the respondents' composition. We interviewed 1015 respondents in total, $52.6 \%$ of them are in the age of 30 - 60 years old, and $33 \%$ are 30 years old. The rest $14.4 \%$ are more than 60 years of age. From an occupation perspective, in the 1015 survey, $13.5 \%$ are farmers, $29.4 \%$ are working in government institutions, $25.6 \%$ in enterprise units, $11.3 \%$ in self-employed businesses and $20.2 \%$ in non-occupation. 
Table 1. Respondents' composition $\mathrm{N}=1015$.

\begin{tabular}{cccc}
\hline & & Frequency & Percent (\%) \\
\hline \multirow{2}{*}{ Age } & $<30$ & 335 & 33.0 \\
& $30-60$ & 534 & 52.6 \\
& $>60$ & 146 & 14.4 \\
Gender & Total & 1015 & 100.0 \\
& male & 597 & 58.8 \\
& Female & 418 & 41.2 \\
Occupation & Total & 1015 & 100.0 \\
& Peasant & 137 & 13.5 \\
& Public institution staff & 298 & 29.4 \\
& Enterprise staff & 260 & 25.6 \\
& Individual businesses & 115 & 11.3 \\
& Unemployed & 205 & 20.2 \\
& Total & 1015 & 100.0 \\
\hline
\end{tabular}

\subsection{Single Variable Analysis}

\subsubsection{The Perception of Pension Risk}

Table 2 demonstrates the respondents' perception of pension risk. Of the 1015 respondents, $36.7 \%$ thought the biggest problem of social pension is the risk of economic support, followed by medical health risk, accounting for $28.9 \%$, the next is the risk of life care, accounting for $18 \%$, and finally the risk of mental support is accounting for $16.4 \%$.

\subsubsection{The Satisfaction of the Social Pension}

Table 3 demonstrates the respondents' satisfaction of the social pension. In the survey, $38.0 \%$ of the respondents evaluate the current social pension system with a satisfaction. $32.4 \%$ are general satisfied with it while the remaining $26.9 \%$ are still not satisfied. Generally speaking, the social pension system is still imperfect. This suggests that there is a lot of space for the social pension system to improve, which also provides an opportunity for non-profit organizations to participate in social pension service.

\subsubsection{The Social Approval Degree of the Organization}

Table 4 demonstrates the respondents' social approval degree of the organization. In all of the 1015 respondents, $81.40 \%$ are willing to accept non-profit organizations to provide social pension services while $18.60 \%$ are opposed to their participation.

\subsubsection{The Assessment of the Organizational Current Situation}

Table 5 demonstrates the respondents' assessment of the organizational current situation. As we can see from the survey, 396 respondents (39.0\%) said that the biggest predicament for non-profit organizations to provide social pension 
Table 2. Pension risk perception $\mathrm{N}=1015$.

\begin{tabular}{ccc}
\hline Type of risk & Frequency & Percent (\%) \\
\hline Life care & 183 & 18.0 \\
Economic support & 373 & 36.7 \\
Spiritual support & 166 & 16.4 \\
Medical and healthy & 293 & 28.9 \\
Total & 1015 & 100.0 \\
\hline
\end{tabular}

Table 3. Pension satisfaction $\mathrm{N}=1015$.

\begin{tabular}{ccc}
\hline & Frequency & Percent (\%) \\
\hline Satisfied & 386 & 38.0 \\
General satisfaction & 356 & 35.1 \\
Not satisfied & 273 & 26.9 \\
Total & 1015 & 100.0 \\
\hline
\end{tabular}

Table 4. The Social approval degree of the organization $\mathrm{N}=1015$.

\begin{tabular}{ccc}
\hline & Frequency & Percent (\%) \\
\hline Yes & 826 & 81.4 \\
No & 189 & 18.6 \\
Total & 1015 & 100.0 \\
\hline
\end{tabular}

Table 5. The assessment of the organizational current situation $\mathrm{N}=1015$.

\begin{tabular}{ccc}
\hline & Frequency & Percent (\%) \\
\hline Lacking trust & 162 & 16.0 \\
limited resources & 320 & 31.5 \\
Nonstandard management & 396 & 39.0 \\
Imperfect mechanism & 137 & 13.5 \\
Total & 1015 & 100.0 \\
\hline
\end{tabular}

services is the nonstandard management. 320 respondents (31.5\%) thought that the greatest difficulty is resource constraints. The participation of non-profit organizations is restrained by the lack of trust and the imperfect mechanism.

\subsection{Bivariate Analysis}

\subsubsection{Age the Social Approval Degree Cross-Tabulation}

Table 6 demonstrates the cross-tab analysis of age and the social approval degree. Among the survey, the age of 335 respondents (33.0\%) is under 30 years old and 534 respondents $(52.6 \%)$ is between 30 years old and 60 years old, and 146 respondents $(14.4 \%)$ is more than 60 years old respectively. Accounting for 81.4 percent and 18.6 percent of the total, there are 826 people who are willing to 
Table 6. Age the social approval degree cross-tabulation $\mathrm{N}=1015$.

\begin{tabular}{|c|c|c|c|c|}
\hline \multirow[b]{2}{*}{ Age } & & \multicolumn{3}{|c|}{ The social approval degree } \\
\hline & & Yes & No & Total \\
\hline \multirow[t]{4}{*}{$<30$} & Count & 287 & 48 & 335 \\
\hline & Percentage in age & $85.7 \%$ & $14.3 \%$ & $100.0 \%$ \\
\hline & Percentage in social approval degree & $34.7 \%$ & $25.4 \%$ & $33.0 \%$ \\
\hline & Percentage of total & $28.3 \%$ & $4.7 \%$ & $33.0 \%$ \\
\hline \multirow[t]{4}{*}{$30-60$} & Count & 426 & 108 & 534 \\
\hline & Percentage in age & $79.8 \%$ & $20.2 \%$ & $100.0 \%$ \\
\hline & Percentage in social approval degree & $51.6 \%$ & $57.1 \%$ & $52.6 \%$ \\
\hline & Percentage of total & $42.0 \%$ & $10.6 \%$ & $52.6 \%$ \\
\hline \multirow[t]{4}{*}{$>60$} & Count & 113 & 33 & 146 \\
\hline & Percentage in age & $77.4 \%$ & $22.6 \%$ & $100.0 \%$ \\
\hline & Percentage in social approval degree & $13.7 \%$ & $17.5 \%$ & $14.4 \%$ \\
\hline & Percentage of total & $11.1 \%$ & $3.3 \%$ & $14.4 \%$ \\
\hline \multirow[t]{4}{*}{ Total } & Count & 826 & 189 & 1015 \\
\hline & Percentage in age & $81.4 \%$ & $18.6 \%$ & $100.0 \%$ \\
\hline & Percentage in social approval degree & $100.0 \%$ & $100.0 \%$ & $100.0 \%$ \\
\hline & Percentage of total & $81.4 \%$ & $18.6 \%$ & $100.0 \%$ \\
\hline
\end{tabular}

accept non-profit organizations to provide social pension services while 189 people are opposed to their participation. According to the analysis of people with different degrees of recognition, we can see that among 826 people who are willing to accept non-profit organizations to participate in social pension services, 287 of them are under 30 years old, 426 of them are 30 - 60 years old, and 113 are over 60 years old, respectively accounting for $34.7 \%, 51.6 \%$ and $13.7 \%$. But people who hold opposing views show that 48 of them are under 30 years old, 108 of them are between 30 - 60 years old, and 33 of them are over 60 years old, accounting for $25.4 \%, 10.6 \%$ and $17.5 \%$.

Table 7 demonstrates that in the Chi-Square Tests, the null hypothesis is $\mathrm{H}_{0}$, which means the social approval degree of the respondents at different ages is consistent. Correspondingly, alternative hypothesis is $\mathrm{H}_{1}$, which means there is a discrepancy in the recognition of the respondents at different ages. When the significance level $\alpha=0.05$, because the probability of chi-square value $\mathrm{p}<0.05$, we should reject the null hypothesis and accept the alternative hypothesis. Namely, we can conclude that the recognition of different age respondents for non-profit organizations is not consistent. In a large number of samples, the likelihood ratio chi square (0.035) and Pearson Chi-square (0.039) are very close, which also proves the test result.

\subsubsection{Occupation the Social Approval Degree Cross-Tabulation}

Table 8 demonstrates the cross-tab analysis of occupation and the social approval degree. According to the analysis of people with different degrees of 
Table 7. Chi-square tests.

\begin{tabular}{cccc}
\hline & Value & df & Asymp. Sig. (2-sided) \\
\hline Pearson Chi-Square & $6.508^{\mathrm{a}}$ & 2 & 0.039 \\
Likelihood Ratio & 6.689 & 2 & 0.035 \\
Linear-by-Linear Association & 6.030 & 1 & 0.014 \\
\hline
\end{tabular}

a. 0 cells $(0.0 \%)$ have expected count less than 5 . The minimum expected count is 27.19.

Table 8. Occupation the social approval degree cross-tabulation $\mathrm{N}=1015$.

\begin{tabular}{|c|c|c|c|c|}
\hline \multirow[t]{2}{*}{ Occupation } & & \multicolumn{3}{|c|}{ The social approval degree } \\
\hline & & Yes & No & Total \\
\hline \multirow[t]{4}{*}{ Peasant } & Count & 108 & 29 & 137 \\
\hline & In age & $78.8 \%$ & $21.2 \%$ & $100 \%$ \\
\hline & In approval degree & $13.1 \%$ & $15.3 \%$ & $13.5 \%$ \\
\hline & Total & $10.6 \%$ & $2.9 \%$ & $13.5 \%$ \\
\hline \multirow[t]{4}{*}{ Public institution staff } & Count & 249 & 49 & 298 \\
\hline & In age & $83.6 \%$ & $16.4 \%$ & $100 \%$ \\
\hline & In approval degree & $30.1 \%$ & $25.9 \%$ & $29.4 \%$ \\
\hline & Total & $24.5 \%$ & $4.8 \%$ & $29.4 \%$ \\
\hline \multirow[t]{4}{*}{ Enterprise staff } & Count & 200 & 60 & 260 \\
\hline & In age & $76.9 \%$ & $23.1 \%$ & $100 \%$ \\
\hline & In approval degree & $24.2 \%$ & $31.7 \%$ & $25.6 \%$ \\
\hline & Total & $19.7 \%$ & $5.9 \%$ & $25.6 \%$ \\
\hline \multirow[t]{4}{*}{ Individual businesses } & Count & 89 & 26 & 115 \\
\hline & In age & $77.4 \%$ & $22.6 \%$ & $100 \%$ \\
\hline & In approval degree & $10.8 \%$ & $13.8 \%$ & $11.3 \%$ \\
\hline & Total & $8.8 \%$ & $2.6 \%$ & $11.3 \%$ \\
\hline \multirow[t]{4}{*}{ Unemployed } & Count & 180 & 25 & 205 \\
\hline & In age & $87.8 \%$ & $12.2 \%$ & $100 \%$ \\
\hline & In approval degree & $21.8 \%$ & $13.2 \%$ & $20.2 \%$ \\
\hline & Total & $17.7 \%$ & $2.5 \%$ & $20.2 \%$ \\
\hline \multirow[t]{4}{*}{ Total } & Count & 826 & 189 & 1015 \\
\hline & In age & $81.4 \%$ & $18.6 \%$ & $100 \%$ \\
\hline & In approval degree & $100 \%$ & $100 \%$ & $100 \%$ \\
\hline & Total & $81.4 \%$ & $18.6 \%$ & $100 \%$ \\
\hline
\end{tabular}

recognition, we can see that among 826 people who are willing to accept non-profit organizations to participate in social pension services, 108 respondents $(10.6 \%)$ are peasants, 249 respondents $(24.5 \%)$ are public institution staffs, 200 respondents $(19.7 \%)$ are enterprise staffs, 89 respondents $(8.8 \%)$ are indi- 
vidual business, and 180 respondents (17.7\%) are Unemployed. Among the 189 people who are unwilling to accept non-profit organizations' participation in social pension services, the proportion is $2.9 \%, 4.8 \%, 5.9 \%, 2.6 \%$ and $2.5 \%$ in proper order.

Table 9 demonstrates that in the Chi-Square Tests, the null hypothesis is $\mathrm{H}_{0}$, which means the social approval degree of the respondents at different occupation is consistent. Correspondingly, alternative hypothesis is $\mathrm{H}_{1}$, which means the social approval degree of the respondents at different occupation is inconsistent. When the significance level $\alpha=0.05$, because the probability of chi-square value $\mathrm{p}<0.05$, we should reject the null hypothesis and accept the alternative hypothesis. Namely, we can conclude that the social approval degree of the respondents at different occupation is inconsistent. In a large number of samples, the likelihood ratio chi square (0.020) and Pearson Chi square (0.017) are very close, which also proves the test result.

\section{Discussion}

1) Through our survey, we can see that the approval degree of the participation of non-profit organizations in social pension service is relatively high. Due to its unique commonweal, non-profit organizations can be used to alleviate the contradiction of demands through the provision of services. On the one hand, the non-profit organizations have direct contact to the elderly group, which knows the real life and demand of the elderly better. By giving suggestions to the government, they can promote the adoption and improvement of relevant policies, which is beneficial to make the policies more scientific and rational. On the other hand, in the current structural reform under the background of supply side, non-profit organizations can carry out the national policies, promote the distribution of social resources, and narrow the gap among different regions by participating in the social pension services.

2) Although the scale and degree of non-profit organization is different, the limitation of geographical space and time is gradually broke by information technology. Non-profit organizations are devoted to push forward their information construction constantly in the process of cooperation with other organizations. The establishment of cooperation is distributed to improve the structure of the supply, increase the supply of services, and realize the maximization of

Table 9. Chi-square tests.

\begin{tabular}{cccc}
\hline & Value & df & Asymp. Sig. (2-sided) \\
\hline Pearson Chi-Square & $11.719^{\mathrm{a}}$ & 4 & 0.020 \\
Likelihood Ratio & 12.095 & 4 & 0.017 \\
Linear-by-Linear Association & 1.835 & 1 & 0.176 \\
N of Valid Cases & 1015 & & \\
\hline
\end{tabular}

a. 0 cells $(0.0 \%)$ have expected count less than 5 . The minimum expected count is 21.41 . 
total social benefits. With the diversification of service type and the gradual saturation of total supply, in order to meet the needs of the elderly better, it is necessary to improve the organizational credibility and creativity. As a result, non-profit organizations will constantly optimize the resource utilization, and improve the efficiency and quality of social pension service supply.

3) The participation of non-profit organizations in social care is also facing with many difficulties. From the inside, there are three aspects. Firstly, the management operation model of some organizations is imperfect. Secondly, they lack the professional and management talents. Thirdly, the organizational credibility needs to be promoted. Due to the development of the non-profit organizations in domestic was still in the primary stage, the attractive ability of salary non-profit organization can afford is weak. It is no denying that there is a certain gap between expected value and practical level for unemployed personnel and professional management talents.

Moreover, the lack of credibility and trust crisis in the current period of social transformation has exacerbated the public distrust of non-profit organizations. From the external point of view, there are three major problems: the inadequate of legal systems, lack of resources support and the imbalance of regional development. On one hand, China's related policy cannot adapt to the development of non-profit organizations, and the lag of legislation is becoming more and more prominent. On the other hand, the essence of the organizations determines that the profit margins of the non-profit organizations are quite narrow. The development of NPO depends on the supports of the state and society to a large extent. Because of the sustained growth of service demand, many non-profit organizations often fail to meet the huge demands and many nonprofit organizations tend to be behindhand in the circumstances.

4) The current pension risk is becoming more and more diverse and people are not satisfied with the current social security system construction. Through the investigation, we can see that the current risks mainly focus on economic support, life care, spirit comfort and health \& medical. With the continuous development of social economy and the continuous improvement of the national social security system, the risks of economic support and health \& medical will reduce gradually. However, for empty-nest elderly who living alone, the problems that lack life care and spirit comfort still exist and will exist for a long time. At the same time, the pension services provided by the government are difficult to meet the needs of the elderly. However, it also provides a space for non-profit organizations to participate in the provision of social pension services for the society. In the West, in response to "welfare crisis", the western theorists put their eyes on non-profit organizations. The practice of Western governments also proved that the make NPO participate in the social pension service is an effective way.

\section{Conclusions}

Non-profit organization (NPO) refers to all voluntary organizations, social or- 
ganizations or non-governmental associations outside government departments and for-profit enterprises, which are the "third sector" between the government and for-profit enterprises. By soliciting social volunteers to provide public welfare services and dealing with special public affairs, Non-profit organizations contribute to help the vulnerable groups and promote social harmony and civilization. This research is benefit to provide some references for exploring the pathways of Non-profit organizations involvement in social pension service.

Non-profit organizations are more of the main body of external resources, while in many underdeveloped rural areas, the development of non-profit organizations is not sufficient. Even in some areas, there are no professional non-profit organizations that can undertake and carry out various services activities. The gap is not only reflected between the urban and rural areas but also in different regions. At present, the development of emerging information technology provides the support and guarantee with the effective allocation of organizational resources as well as internal and external linkage. The application of information technology in society has begun to come into shape, and the practice of exploration and innovation is being explored everywhere constantly. The networked synergy and intelligence of multiple principal resources may be the further development trend of social pension model in the future.

All in all, social endowment is a very complicated dynamic system, which involves wide elements. Therefore, social pension services need not only the participation of non-profit organizations, but also the cooperation between the government, enterprises and the public. The aging of the population is the inevitable product of the social and economic development of human beings, which is also an important symbol of the civilization and progress of the society. China is in the period of social transformation, the social environments are changing rapidly. In order to build a multivariate synergy pattern, government should adjust the original development strategy and adhere to the "comprehensive, coordinated, sustainable and harmonious concept". As a potential social capital, non-profit organization is an important force for assisting the work of care for the aged, which should participate in the pension services actively by surmounting the obstacles of geographic location and making the organizational resources flow flexibly. Aiming at achieving accurate, effective and sustainable service supply for the elderly, the multiple subjects should cooperate with each other to meet the basic demands of the aged people and the aged group for residence, cares, medical service, studies, work and entertainment.

\section{References}

[1] United Nations Department of Economic and Social Affairs (2017) World Population Prospects: The 2017 Revision. United Nations Department of Economic and Social Affairs, New York.

[2] United Nations Department of Economic and Social Affairs (2017) The Household Living Arrangements of Older Persons (Percentage) from the UN Database of the Living Arrangements of Older Persons, 2017. United Nations Department of Eco- 
nomic and Social Affairs, New York.

[3] Hu, H.W., et al. (2012) Squeezing or Squeezing out: The Impact of Social Security on the Children's Economic Support for the Elderly-On Medical Security and Family Economic Support. Population Research, 2, 82-96.

[4] Qian, Y.X. (2014) The Research on Social Pension Service System under the Background of Aging. Theoretical Investigation, 1, 162-165.

[5] Zhang, Y.H. and Jiang, Y. (2015) The Status Quo of China's Old-Age Service, Problems and Public Policy Choices. Contemporary Economic Management, 37, 51-56.

[6] Wei, W.B., et al. (2013). The Model Construction and Pathways of Social Old-Age Service System. Journal of Soochow University (Philosophy \& Social Science Edition), 34, 48-52. 